\title{
Appropriateness of computed tomography and magnetic resonance imaging scans in the Eden and Central Karoo districts of the Western Cape Province, South Africa
}

J Becker, ${ }^{1} \mathrm{MB}$ ChB; L S Jenkins, ${ }^{2} \mathrm{MB}$ ChB, MFamMed, FCFP (SA), PhD; M de Swardt,${ }^{2} \mathrm{MB}$ ChB; R Sayed, ${ }^{3} \mathrm{MSc} ; \mathbf{M}$ Viljoen, ${ }^{4} \mathrm{MB}$ ChB

${ }^{1}$ Knysna Provincial Hospital, Western Cape, South Africa

${ }^{2}$ Department of Family Medicine, George Provincial Hospital, Western Cape, South Africa

${ }^{3}$ School of Public Health and Family Medicine, Faculty of Health Sciences, University of Cape Town, South Africa

${ }^{4}$ George Provincial Hospital, Western Cape, South Africa

Corresponding author: J Becker (juanitabecker7@gmail.com)

\begin{abstract}
Introduction. Computed tomography (CT) and magnetic resonance imaging (MRI) are an essential part of modern healthcare. Marked increases in clinical demand for these imaging modalities are straining healthcare expenditure and threatening health system sustainability. The number of CT and MRI scans requested in the Eden and Central Karoo districts of the Western Cape Province, South Africa (SA), almost doubled from 2011 to 2013.

Objective. To determine the appropriateness of CT and MRI scans and relate this to the requesting department and clinician.

Methods. This was a retrospective analytical cohort study. All scans during October 2012 were analysed as a sample. Appropriateness of scans was determined using the American College of Radiologists (ACR) Appropriateness Criteria and the Royal College of Radiology Guidelines. Appropriateness was also correlated back to the requesting department and clinician.

Results. Of a total of 219 scans, $53.0 \%$ were abnormal. Overall $6.4 \%$ of scans were considered inappropriate. Interns and registrars requested no inappropriate scans. The orthopaedics department scored the highest rate of appropriate scans (80.0\%) and the oncology department the highest rate of inappropriate scans $(20.8 \%)$.

Conclusion. The limited resources available for healthcare in a developing country like SA should be a motivation to implement control mechanisms aimed at appropriate utilisation of imaging examinations. The Eden and Central Karoo districts have a low rate of inappropriate scans (6.4\%). We recommend that the current preauthorisation system by consultants and other senior clinicians continues, but with increased clinician awareness of the ACR Appropriateness Criteria and the Royal College guidelines.
\end{abstract}

S Afr Med J 2014;104(11):762-765. DOI:10.7196/SAMJ.8158

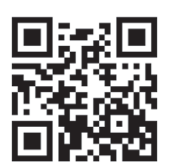

Computed tomography (CT) and magnetic resonance imaging (MRI) have become an essential part of modern healthcare. ${ }^{[1]}$ It would seem intuitive that, by enabling the practitioner to make non-invasive diagnoses, these investigations should improve health outcomes in many individuals, but this is often difficult to prove. However, marked increases in imaging utilisation are now straining healthcare expenditure and threatening health system sustainability. ${ }^{[1]}$ Imaging is one of the fastest-growing services in medicine; it is estimated that imaging costs amount to $\$ 100000$ billion annually in the USA. ${ }^{[2]}$ In the past decade technological advances in CT and MRI have further increased their clinical utilisation. ${ }^{[3]}$ The clinical information obtained and their greater accessibility have made them attractive to both patients and referring doctors.

However, the increased utilisation of diagnostic imaging has brought with it significant economic and medical risks. Brenner and Hall ${ }^{[4]}$ have highlighted the alarming increase in radiation exposure through CT and the accompanying carcinogenic potential. Recent work also emphasised the growing concern about unforeseen contrast-related severe reactions such as gadolinium-related nephrogenic systemic fibrosis, over and above the well-known mild allergies and anaphylactoid responses. ${ }^{[5]}$

According to a World Bank report in 2009, health expenditure in South Africa (SA) was $8.5 \%$ of the gross domestic product. This was considerably higher than the $5 \%$ recommended by the World Health Organization. The national Minister of Health, Dr Aaron Motsoaledi, has stated that 'We exceed our healthcare costs ... We are a country spending more on health but having poor outcomes.' It is therefore essential to regulate costs in our health system, which includes the cost of imaging. ${ }^{[6]}$

Levy et al. ${ }^{[7]}$ investigated the effect of the American College of Radiologists (ACR) Appropriateness Criteria and found an increase in appropriate MRI examinations after applying these criteria. It has been shown that a telephonic preauthorisation process for radiological studies also produced a statistically significant change in the rate of ordering MRI studies, but not CT scans. ${ }^{[8]}$

A study undertaken in Israel ${ }^{[9]}$ assessed the effect of a managed care preauthorisation programme based on the ACR Appropriateness Criteria and the Royal College of Radiology Guidelines. Before preauthorisation was compulsory, CT and MRI utilisation rates were constantly increasing, by $20 \%$ and $5 \%$ per year for CT and MRI, respectively. After implementation of preauthorisation, CT and MRI annual request rates decreased from 25.9 and 7 examinations per 1000 patients in 2000 to 17.3 and 5.6 in 2003. CT was more commonly inappropriately utilised by the paediatric group, while medical subspecialties more commonly utilised MRI inappropriately. Preauthorisation of CT and MRI requests resulted in a substantial decrease in utilisation and imaging costs. ${ }^{[9]}$

In the Eden and Central Karoo districts in the Western Cape Province of SA, CT and MRI services requested in the public sector were historically outsourced to the private sector (Fig. 1). In 2011 the Eden District had a population of approximately 563573 people, of whom $89 \%$ had no medical insurance. 


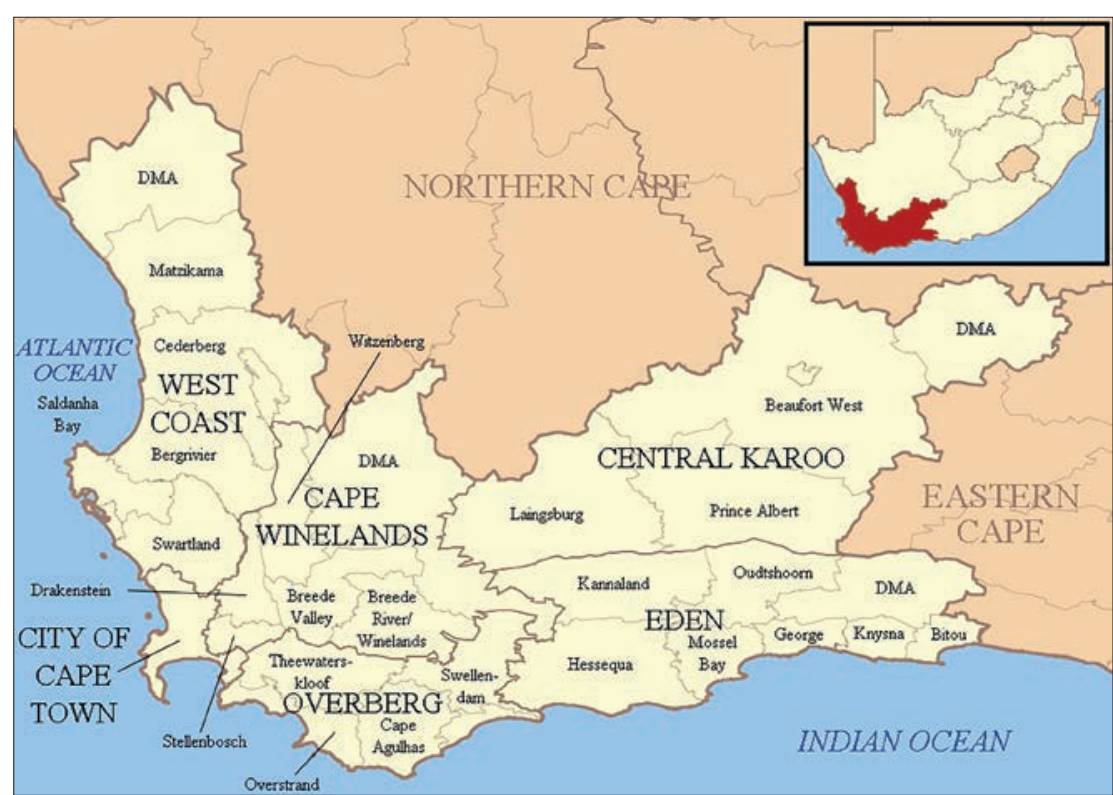

Fig. 1. Map of the health districts and subdistricts in the Western Cape Province, SA. (SA = South Africa.)

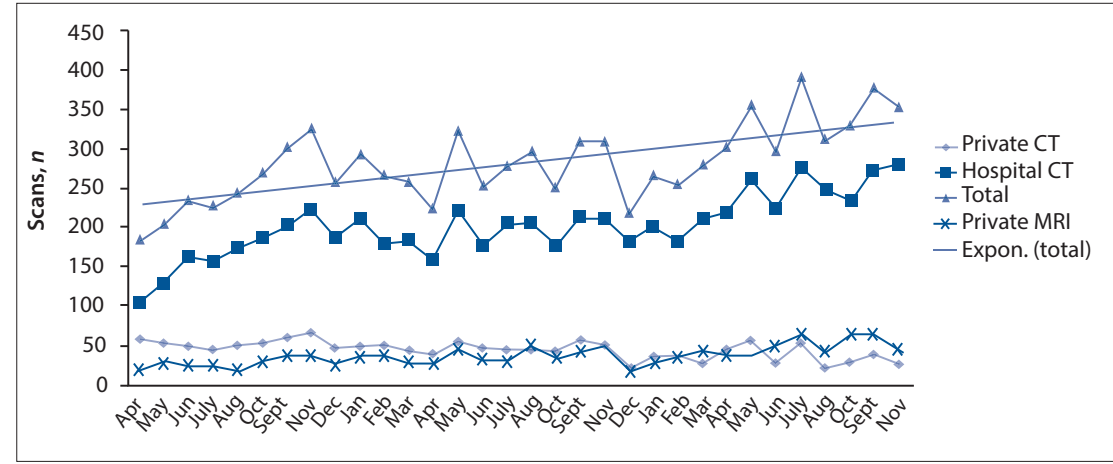

Fig. 2. CT and MRI scans done in the Eden and Central Karoo districts of the Western Cape Province, SA, from April 2011 to November 2013. (CT = computed tomography; MRI = magnetic resonance imaging; $S A=$ South Africa.)

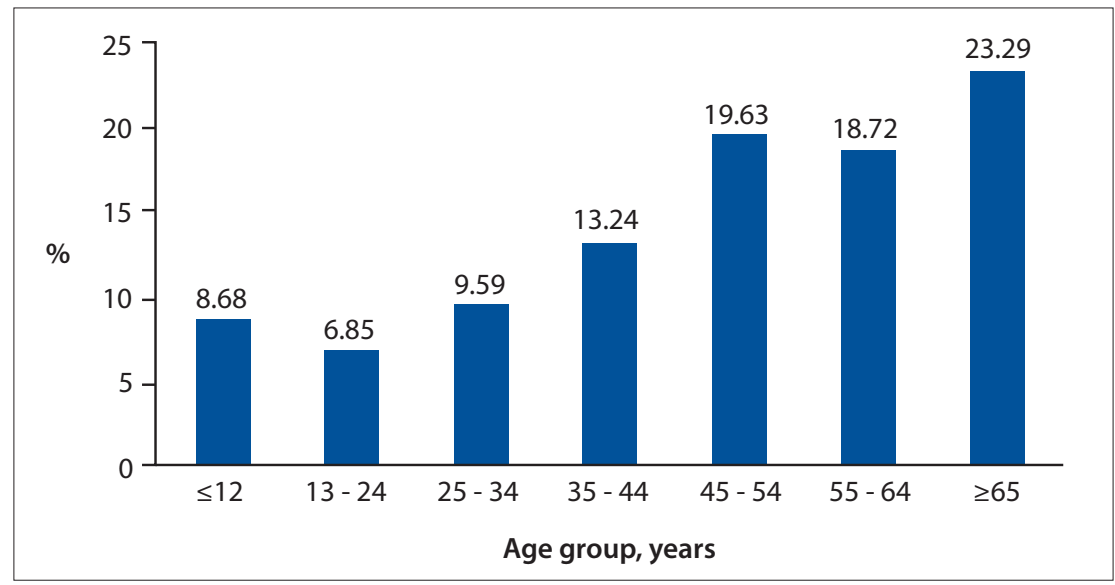

Fig. 3. Age distribution of the study population.

In November 2010, George Hospital obtained and started operating its own CT scanner. Subsequently the number of CT and MRI scans requested in the Eden and Central Karoo districts almost doubled between April 2011 and November 2013 (Fig. 2). There were no data available on the appropriateness of CT and MRI scans in these districts. The aim of this study was to determine the appropriateness of CT and MRI scans in the districts and relate their appropriateness score to the requesting department and clinician.

\section{Methods}

This was a retrospective analytical cohort study. All public sector scans done in the Eden and Central Karoo districts during October 2012 were included. The folders of all patients at George Hospital who underwent private or state sector CT or MRI scans were retrieved from the hospital. The demographic data, type of scan, indication for the scan, requesting practitioner and requesting department were obtained from the notes. Folders with incomplete data were excluded from the study. Public sector patients who had scans done in private practice at Knysna or Mossel Bay provincial hospitals were not included in the study, as it was not possible to access their folders. During the study period 25 and 42 state patients had CT and MRI scans done in private practice in Mossel Bay and Knysna, respectively.

Appropriateness of CT and MRI scans was determined by using the ACR Appropriateness Criteria and the Royal College of Radiology Guidelines. ${ }^{[10]}$ The ACR Appropriateness Criteria uses the following rating scale: 1, 2, 3 'usually not appropriate', 4, 5, 6 'may be appropriate', and 7, 8, 9 'usually appropriate. Cases in which an ACR code could not be assigned were labelled ACR non-codable.

Data were captured and analysed using Microsoft Excel 2003 software. Statistical support was offered by the School of Public Health and Family Medicine, University of Cape Town. The study was approved by the Human Ethics Committee of the University of Cape Town (HREC REF: 132/2013).

\section{Results}

A total of 251 scans were performed during the study period, 219 of which were included in the study. The mean age of the population sampled was 47.6 years (Fig. 3 ).

The Eden district has seven subdistricts. Table 1 compares the total population size of each subdistrict $(2011)^{[11]}$ with the number of CT and MRI scans requested. Scans performed in the private sector are not included.

The majority of CT scans requested were of the brain $(48.4 \%)$, and a total of 27 MRI scans were requested (Table 2 ).

As judged by the reports, $31.5 \%$ of scans were normal, $53.0 \%$ were abnormal and $15.5 \%$ were 'abnormal as expected' (scans in patients who had known pathology, but no new pathology noted).

Using the ACR criteria, $6.4 \%$ of scans were found to be inappropriate, $15.5 \%$ 
Table 1. Population size of each subdistrict (2011) in relation to the number of scans requested

\begin{tabular}{llll}
\hline Subdistrict & Total population & Scans, $\boldsymbol{n}$ & $\begin{array}{l}\text { \% of subdistrict } \\
\text { population scanned } \\
\text { in October 2012 }\end{array}$ \\
\hline George & 188236 & 114 & 0.06 \\
Hessequa & 46296 & 13 & 0.02 \\
Kannaland & 28505 & 7 & 0.02 \\
Knysna & 60564 & 28 & 0.05 \\
Bitou & 48763 & 2 & 0.004 \\
Mossel Bay & 101544 & 19 & 0.02 \\
Oudtshoorn & 92545 & 27 & 0.03 \\
Other & & 9 & \\
Total & & 219 & \\
& & &
\end{tabular}

Table 2. Anatomical areas scanned

\begin{tabular}{|c|c|}
\hline Type of scan & $n(\%)$ \\
\hline \multicolumn{2}{|l|}{ CT } \\
\hline Brain & $106(48.4)$ \\
\hline Chest & $27(12.3)$ \\
\hline Abdomen & $23(10.5)$ \\
\hline Cervical spine & $7(3.2)$ \\
\hline Abdomen and pelvis & $6(2.7)$ \\
\hline Angiogram of legs & $5(2.3)$ \\
\hline Whole body & $4(1.8)$ \\
\hline Renal arteries/renal tract & $4(1.8)$ \\
\hline Brain and orbits & $3(1.4)$ \\
\hline Pulmonary angiogram & $2(0.9)$ \\
\hline Brain and facial bones & $2(0.9)$ \\
\hline Pelvis & $1(0.5)$ \\
\hline Sinuses & $1(0.5)$ \\
\hline Cerebral angiogram & $1(0.5)$ \\
\hline \multicolumn{2}{|l|}{ MRI } \\
\hline Lumbar spine & $11(5.0)$ \\
\hline Brain & $4(1.8)$ \\
\hline Cervical spine & $4(1.8)$ \\
\hline Pelvis & $4(1.8)$ \\
\hline Whole spine & $2(0.9)$ \\
\hline Thoracic spine & $1(0.5)$ \\
\hline Femur & $1(0.5)$ \\
\hline Total & $219(100)$ \\
\hline
\end{tabular}

'may be appropriate', $63.5 \%$ were appropriate and $14.6 \%$ were ACR non-codable. Table 3 relates appropriateness to the rank of the requesting practitioner. Interns and registrars requested no inappropriate scans.
Table 4 relates appropriateness to the requesting department. The orthopaedics department had the highest percentage of appropriate scans $(80.0 \%)$, while the oncology department had the highest percentage of inappropriate scans $(20.8 \%)$.

\section{Discussion}

Almost two-thirds (64\%) of the scans performed at George Hospital were found to be appropriate using the ACR Appropriateness Criteria. This compares favourably with a study from the University of Washington that retrospectively analysed 459 CT and MRI scans for appropriateness using evidence-based guidelines. ${ }^{[12]}$ In this study, clinical history submitted at the time of interpretation, the clinical notes and laboratory results preceding the date of the imaging were evaluated. The radiology reports and subsequent clinic visits were measured for outcomes, and $74 \%$ of scans were found to be appropriate. Examples of inappropriate scans included brain CT for chronic headache, lumbar spine MRI for acute back pain, knee or shoulder MRI in patients with osteoarthritis, and CT scans for haematuria during a urinary tract infection. ${ }^{[12]}$

It is essential that doctors know how to select the appropriate imaging technique to ensure cost-effective, high-quality patient care. $^{[13]}$ The ACR developed its Appropriateness Criteria in 1993, and ongoing revisions have kept them relevant. These are expertgenerated, evidence-based guidelines intended to guide referring doctors in the correct use of diagnostic and interventional radiology for given clinical situations. ${ }^{[10]}$ However, it has been shown that in the USA there is low utilisation of the ACR Appropriateness Criteria by clinicians when ordering imaging studies for their patients. ${ }^{[14]}$

In our study, most of the scans were performed in the $>65$ years age group and very few were performed in patients aged $<12$ years. This is excellent practice in terms of reducing radiation exposure in children, yet the paediatrics department was found to have an $18.7 \%$ rate of inappropriate scans, despite a general perception that the department is very judicious in the ordering of CT scans. According to the ACR Appropriateness Criteria, MRI scans are preferred in children because of the reduced radiation exposure. It is, however, difficult to order MRI scans for children at George Hospital, as they have to be performed in the private sector, necessitating transport to the private hospital, and a doctor has to accompany the child for sedation purposes due to the claustrophobic tunnel and the noise generated by the MRI machine. CT scans, which can be done at George Hospital, therefore tend to be preferred.

When comparing the numbers of scans on patients from the various subdistricts in Eden, there is a clear discrepancy. Far more scans are requested from George Hospital compared with the peripheral hospitals, but this probably reflects the referral nature of George Hospital. The George region has a population of 188236 and generated 114 scans $(0.06 \%$ of the population), while Oudtshoorn, with a population of 92545 , generated only 27 scans (0.03\%). Patients have to travel $65 \mathrm{~km}$ from Oudtshoorn to George Hospital via ambulance to have a scan, while patients in George have easier access to scans. The question arises whether George is perhaps doing too many scans, or the peripheral hospitals are doing too few.

Looking at appropriateness of scans in relation to the requesting practitioner, we found that interns ordered no inappropriate scans, while $5.4 \%$ of those ordered by consultants were inappropriate. One explanation could be that interns tend to make decisions on the more straightforward scans with clear appropriateness guidelines, while scans that need approval by a consultant typically include more difficult clinical situations. Alternatively, the intern may have only been directed to request the scan after senior clinician input. 
Table 3. Appropriateness of scan in relation to requesting practitioner rank

\begin{tabular}{llllll}
\hline Practitioner & $\begin{array}{l}\text { Inappropriate } \\
\boldsymbol{n}(\%)\end{array}$ & $\begin{array}{l}\text { May be appropriate } \\
\boldsymbol{n}(\%)\end{array}$ & $\begin{array}{l}\text { Appropriate } \\
\boldsymbol{n}(\%)\end{array}$ & $\begin{array}{l}\text { Non-codable } \\
\boldsymbol{n}(\%)\end{array}$ & $\begin{array}{l}\text { Total } \\
\boldsymbol{N}(\%)\end{array}$ \\
\hline Consultant & $6(5.4)$ & $13(11.6)$ & $71(63.4)$ & $22(19.6)$ & $112(100)$ \\
Intern & $0(0)$ & $3(33.3)$ & $6(66.7)$ & $0(0)$ & $9(100)$ \\
Medical officer & $4(4.8)$ & $15(18.3)$ & $54(65.8)$ & $9(11.0)$ & $82(100)$ \\
Registrar & $0(0)$ & $3(33.3)$ & $6(66.7)$ & $0(0)$ & $9(100)$ \\
Unknown & $4(57.1)$ & $0(0)$ & $2(28.6)$ & $1(14.3)$ & $7(100)$ \\
Total & $14(6.4)$ & $34(15.5)$ & $139(63.5)$ & $32(14.6)$ & $219(100)$
\end{tabular}

Table 4. Appropriateness of scans in relation to the requesting department

\begin{tabular}{llllll}
\hline Department & $\begin{array}{l}\text { Inappropriate } \\
\boldsymbol{n}(\%)\end{array}$ & $\begin{array}{l}\text { May be appropriate } \\
\boldsymbol{n}(\%)\end{array}$ & $\begin{array}{l}\text { Appropriate } \\
\boldsymbol{n}(\%)\end{array}$ & $\begin{array}{l}\text { Non-codable } \\
\boldsymbol{n}(\%)\end{array}$ & $\begin{array}{l}\text { Total } \\
\boldsymbol{N}(\%)\end{array}$ \\
\hline Cardiothoracic outreach & $0(0)$ & $0(0)$ & $0(0)$ & $1(100)$ & $1(100)$ \\
Ear, nose and throat & $0(0)$ & $1(50.0)$ & $1(50.0)$ & $0(0)$ & $2(100)$ \\
Family medicine & $1(4.2)$ & $5(20.8)$ & $17(70.8)$ & $1(4.2)$ & $24(100)$ \\
Internal medicine & $0(0)$ & $15(20.8)$ & $49(68.1)$ & $8(11.1)$ & $72(100)$ \\
Oncology & $5(20.8)$ & $6(25.0)$ & $9(37.5)$ & $4(16.7)$ & $24(100)$ \\
Ophthalmology & $0(0)$ & $1(100)$ & $0(0)$ & $0(0)$ & $1(100)$ \\
Orthopaedics & $1(4.0)$ & $1(4.0)$ & $20(80.0)$ & $3(12.0)$ & $25(100)$ \\
Paediatrics & $3(18.7)$ & $1(6.2)$ & $5(31.2)$ & $7(43.7)$ & $16(100)$ \\
Psychiatry & $0(0)$ & $1(33.3)$ & $0(0)$ & $2(66.7)$ & $3(100)$ \\
Surgery & $4(8.3)$ & $3(6.2)$ & $35(72.9)$ & $6(12.5)$ & $48(100)$ \\
Urology & $0(0)$ & $0(0)$ & $3(100)$ & $0(0)$ & $3(100)$ \\
Total & $14(6.4)$ & $34(15.5)$ & $139(63.5)$ & $32(14.6)$ & $219(100)$
\end{tabular}

\section{Recommendations}

While almost two-thirds of scans were considered appropriate, and no inappropriate scans were requested by interns or registrars, we recommend that the current 'preauthorisation' system, where consultants are required to grant permission in complex clinical cases, continue at George Hospital, but with an increased sensitivity and awareness of the ACR Appropriateness Criteria. This is particularly true for the oncology department, where a more in-depth study may reveal reasons for requests for some apparently inappropriate scans. Finally, improved access for scans from district hospitals may warrant attention.

\section{Conclusions}

The introduction and ongoing improvement of sophisticated new diagnostic imaging modalities, particularly CT and MRI, have increased utilisation by clinicians dramatically over the past decade. The limited resources available for healthcare in a developing country like SA ought to be motivation to implement control mechanisms aimed at appropriate utilisation of imaging examinations. While this study showed $63.5 \%$ of scans to be appropriate, we also identified concerns around access to scans for district hospitals in the periphery, and a relatively high proportion of inappropriate scans requested by clinicians in the departments of oncology and paediatrics.

Acknowledgements. The authors thank George Hospital management for their support of this study.

\section{References}

1. You JJ. Appropriateness: The next frontier in the quest for better access to CT and MRI. Healthc $Q$ 2009;12(4):25-27. [http://dx.doi.org/10.12927/hcq.2013.21122]

2. Mishori R. The danger of too many tests. Parade, 6 July 2008. www.parade.com/articles/editions/2008 edition_07-06 2008/3Too_Many_Tests (accessed 28 January 2013).

3. Bhargavan $\mathrm{M}$, Sunshine $\mathrm{JH}$. Utilization of radiology services in the United States: Levels and trends in modalities, regions, and populations. Radiology 2005;234(3):824-832. [http://dx.doi.org/10.2214/ AJR.08.1622]

4. Brenner DJ, Hall EJ. Computed tomography: An increasing source of radiation exposure. N Engl I Med 2007;357(22):2277-2284. [http://dx.doi.org/10.1056/NEJMra072149]

5. Wiginton $\mathrm{CD}$, Kelly B, Oto A, et al. Gadolinium-based contrast exposure, nephrogenic systemic fibrosis and gadolinium detection in tissue. Am J Radiol 2008;190(4):1060-1068. [http://dx.doi.org/10.2214/ AJR.07.2822]

6. Motsoaledi: South Africa’s healthcare declining. Mail \& Guardian, 7 September 2012, http://mg co. .z/ article/2012-09-07-motsoaledi-sa-health-care-declining (accessed 2 February 2013).

7. Levy G, Blachar A, Goldstein L, et al. Nonradiologist utilization of American College of Radiology Appropriateness Criteriaste Radiol 2005;187(4):855-858. [http://dx.doi.org/10.2214/AJR.05.1055] Smulowitz PB, Ngo L, Epstein SK. The effect of a CT and MR preauthorization program on ED utilization. Am J Emerg Med 2008;27(3):328-332. [http://dx.doi.org/10.1016/j. ajem.2008.03.012]

9. Blachar A, Tal S, Mandel A, et al. Preauthorization of CT and MRI examinations: Assessment of a managed care preauthorization program based on the ACR Appropriateness Criteria and the Royal a managed care preant Guiation program based on the ACR Approprateness Crite

Americes Appropriateness-Criteria (accessed 2 February 2013).

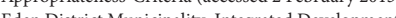

2014/2015. Found at www.westerncape.gov. za/text/2014/April/eden-draft-idp-2014-15.pdf (accessed 26 September 2014).

12. Lehnert BE, Bree RL. Analysis of appropriateness of outpatient CT and MRI referred from primary Lehnert BE, Bree RL. Analysis of appropriateness of outpatient CT and MRI referred from primary
care clinics at an academic medical center: How critical is the need for improved decision support? Am Coll Radiol 2012;7(3):192-197. [http://dx.doi.org/10.1016/j.jscr.2009.11.010]

13. Bettmann M. The ACR appropriateness criteria: View from the committee chair. J Am Coll Radiol 2006;3(7):510-512. [http://dx.doi.org/10.1016/j.jscr.2006.03.024]

14. Bautista AB, Burgos A, Nickel BJ, Yoon JJ, Tilara AA, Amorosa JK. Do clinicians use the American College of Radiology Appropriateness Criteria in the management of their patients? AJR Am J Roentgenol 2008;192(6):1581-1585. [http://dx.doi.org/10.2214/AJR.08.1622]

Accepted 1 July 2014. 